Udall, R. H. (1959). Am. F. vet. Res. 20, 423.

Udall, R. H. (1962). Am. F. vet. Res. 23, 1241.

Udall, R. H. \& Chen Chow, F. H. (1963). Ann. N.Y. Acad. Sci. 104, 612.

Udall, R. H. \& Chen Chow, F. H. (1965). Cornell Vet. 55, 538.

Vermeulen, C. W., Lyon, E. S. \& Fried, F. A. (1965). F. Urol. $94,176$.

\author{
Mycotoxins in ruminants \\ By M. C. LanCaster, Nuffield Unit for Laboratory Animal Pathology, \\ University of Edinburgh
}

\title{
Introduction
}

Mycotoxins have for long been associated with disease and death in animals, but because of the great variety of fungi present in animal feedstuffs and the detailed investigations needed to establish a causal relationship between mycotoxin and a clinical disease, few disease syndromes have been identified.

In this paper, it is proposed to consider three confirmed clinical diseases caused by mycotoxins, to review briefly their history and identification and to consider their biological effects in ruminants.

The three mycotoxins are ergot toxin, from the fungus Claviceps purpurea, sporidesmin from Pithomyces chartarum and aflatoxin from Aspergillus flavus. Of these, ergot toxin is the most familiar and has spectacular clinical effects; it causes one of the oldest diseases to be identified in the literature, but confirmed outbreaks of disease are rare in the UK. Sporidesmin, a primary hepatotoxin, is the causal agent of facial eczema of sheep in New Zealand. This is an economically important disease, and although it has been described and its causal agent the fungus Pichartarum is known, control under field conditions is still very difficult. Aflatoxins may be common contaminants of groundnut and cottonseed meals and are potent hepatocarcinogens for the rat.

Although these diseases present a primary problem in the ruminant, there is the secondary question of tissue residues and their possible hazard to man.

\section{Ergot poisoning}

Mycotoxins have long been associated with disease and death in ruminants; and probably the oldest accounts are of poisoning by ergot, the fungus Claviceps purpurea growing on cereals and in particular on rye. Some of the records of this disease go back for more than a century, but the evidence is not always very satisfactory (Barger, 1931).

In cattle, the diagnostic lesions are the development of gangrene of the extremities. There are many confirmed outbreaks of disease in ruminants. In one such severe outbreak involving a herd of forty-three cows and heifers in the UK, sixteen had severe gangrene of the extremities, but none aborted (Dring, 1955).

By feeding ergot to cattle in New Zealand, Cunningham, McIntosh \& Swan (1944) produced the clinical symptoms of gangrene of the extremities, but neither the milk or meat contained any toxic residues (Cunningham, 1949). These workers 
also fed Claviceps purpurea, on perennial ryegrass, to sheep and reported the development of ulceration and inflammation of the alimentary tract, but not the development of gangrene of the extremities; however, cattle fed the same sample of ergot did develop gangrene (Cunningham, Swan \& Hopkirk, 1944).

Also in New Zealand, Hopkirk (1936) fed Claviceps paspali to sheep and noted the predominantly nervous symptoms, with incoordination. This disease is termed 'paspalum staggers'.

\section{Facial eczema}

History. Facial eczema is a serious disease of sheep in the North Island of New Zealand. The name is derived from the clinical features. Typical cases show acute inflammation and oedema, and later necrosis, of the skin of the parts of the face and ears not covered by wool. Ever since improved pastures became established, outbreaks in the late summer and early autumn have been frequent. A particularly severe and widespread outbreak occurred in 1936 .

The investigations which followed this and other outbreaks (New Zealand Society of Animal Production, 1959) showed that the outbreaks occurred in late summer and early autumn, in warm sunny weather after rain, when the grass was growing rapidly. Both sheep and cattle of all ages could be affected, but not horses or pigs grazing the same pasture. In New Zealand, in general, little or no concentrates or hay are fed to sheep, except in the winter during the period of least grass growth or in periods of prolonged drought.

The sheep may show jaundice, as well as the skin lesions, and the main pathological lesion was found to be in the liver, with acute inflammation of the bile ducts. The photosensitization was shown to be the result of the accumulation of plant pigments, which the damaged liver could not detoxicate; these pigments sensitize the skin, so that exposure to bright sunlight causes an acute inflammatory reaction, a mechanism which is thought to involve the liberation of histamine.

After much investigation the fungus Pithomyces chartarum (formerly Sporidesmium bakeri) was incriminated as the cause, and the toxin, was extracted and termed 'sporidesmin'. The toxin is present in highest concentration in the fungal spores. The fungus is found in many countries, growing on dead plant material, but the optimum growth requirements are $100 \%$ relative humidity and a minimum temperature of $13^{\circ}$. These requirements prevent extensive development of the fungus in the South Island of New Zealand and in the UK.

Pathology. At post-mortem examination of affected sheep, the cut surface of the liver may show thickening and oedema of the bile ducts and of the gall bladder, while the bile ducts may contain inspissated bile. Less severe cases may show local areas of necrosis, which radiate from an occluded bile duct.

Histology. Microscopic examination of the liver shows oedema and inflammatory cell infiltration round the bile ducts, and necrosis of the bile duct epithelium. The macroscopic lesions are seen as coagulative necrosis of hepatic cells and proliferation of the bile duct cells from the adjacent surviving portal tracts, and these lesions usually develop at points proximal to obstruction of the duct. 
In outbreaks of the disease mortality may be low, but loss of condition can be severe. Regeneration of the liver after damage is good, and sheep may be exposed to subclinical damage several times in their life or even in the same year. Regenerated areas of liver can be seen when the ewes are slaughtered. They may be multi-lobular or thick and rounded, rather like a curling stone, with only a trace of the original edge of the liver.

Metabolism and excretion. Recent studies, using sheep with a biliary fistula, (Mortimer \& Stanbridge, I968) showed that following a single oral dose $(\mathrm{I} \cdot 0 \mathrm{mg} / \mathrm{kg}$ body-weight) of purified 'sporidesmin' the toxin could be detected in the bile within Io min, reached a maximum in $2-8 \mathrm{~h}$ and was all excreted by $24 \mathrm{~h}$. In the urine the maximum concentration was reached at $\mathrm{I} 2 \mathrm{~h}$, and in the serum the maximum was reached between 15 min and $12 \mathrm{~h}$. The toxin was found to be concentrated tenfold between the serum and urine and a hundredfold between serum and bile. These findings help to explain the severe lesions of the biliary tract.

No sporidesmin or toxic metabolite could be detected in the milk of lactating ewes.

\section{Aflatoxin}

The toxic effects of this mycotoxin were first described when Blount (I96I) and Asplin \& Carnaghan (196r) showed that high mortality in turkey poults and ducklings was caused by inclusion of certain batches of groundnut meal in their diets. Subsequent deaths in pigs (Loosmore \& Harding, 1961) and cattle (Loosmore \& Markson, 196r) were attributed to the same cause.

The toxic factor was first extracted from the meal by Allcroft, Carnaghan, Sargeant \& O'Kelly (196r) and later shown to be a metabolite of certain strains of the common saprophytic fungus Aspergillus flavus (Sargeant, Sheridan, O'Kelly \& Carnaghan (196r).

This toxic factor was given the name aflatoxin (Agricultural Research Council et al. I962) as it was at that time thought to be a single substance. It was soon found that it was a mixture of related fluorescent compounds to which the terms aflatoxin $B_{1}, G_{1}, B_{2}$, and $G_{2}$ were applied, to denote the blue and green fluorescences respectively in ultraviolet light.

Under natural conditions, aflatoxin $B_{1}$ and $G_{1}$ are the metabolites usually present in the greatest proportions in contaminated foods, and the proportions of $B_{2}$ and $G_{2}$ are relatively small, but a mixture of all four components is not infrequently found. Of these four components aflatoxin $B_{1}$ has the lowest $L_{5}$ o for several species (Wogan, I966).

The structural formula for aflatoxin $\mathbf{B}_{\mathbf{1}}$ was reported by Assao, Buchi, Abdel-Kader, Chang, Wick \& Wogan ( 1963 ) and confirmed by van der Zijden, Koelensmid, Boldingh, Barrett, Ord \& Philp (1962). The formulae for $G_{1}, B_{2}$ and $G_{2}$ were reported by Hartley, Nesbitt \& O'Kelly (1963).

In susceptible species a common feature was liver damage with marked bile-duct proliferation, death of hepatic parenchymal cells, and enlarged hepatic cells (megalocytes).

A marked difference was noted in the susceptibility of different species to the 
effect of toxic groundnut meal when $10-25 \%$ was fed as part of the diet. Three different groups could be distinguished, the highly susceptible, the susceptible and the apparently resistant. Examples include turkey poults and ducklings as highly susceptible, calves and pigs as susceptible and mice and sheep as resistant (Allcroft \& Lancaster, I963). In all susceptible species the young are more susceptible than the adults. In view of the great differences in content of aflatoxin $B_{1}$ in contaminated feedstuffs, further results should be related to amounts of aflatoxins fed.

The toxic groundnut meal was shown to be a potent liver carcinogen in the rat (Lancaster, Jenkins \& Philp, 196I), and further work confirmed that the carcinogen was a fungal metabolite (Roe $\&$ Lancaster, 1964). The hepato-carcinogenic effect of the toxic groundnut meal has been confirmed (le Breton, Frayssinet \& Boy, I962; Newberne, 1965), and the carcinogenic action of the purified aflatoxins was shown by Barnes \& Butler (1964) and Butler \& Barnes (1963).

The amount of aflatoxin needed to produce liver tumours in rats varies with the strain. In comparison with other known liver carcinogens in the rat, it has been found that of rats fed to $\mu \mathrm{g}$ aflatoxin daily, five out of six developed hepatic tumours, and liver tumours were also found in rats fed $5 \mu \mathrm{g}$ aflatoxin daily, while for rats of the same strain the carcinogenic level of dimethylnitrosamine is $0.75 \mathrm{mg}$ daily, and of 4-dimethylaminoazobenzene is about $9 \mathrm{mg}$ daily (Butler \& Barnes, 1963). These authors concluded that 'Aflatoxin would appear to be one of the most active carcinogenic substances known'.

Further studies have shown aflatoxins to be carcinogenic in a number of species, including the ferret (Allcroft \& Lancaster, I969), duck (Carnaghan 1965) and trout (Halver, 1965).

It can be seen that aflatoxin is a most potent liver toxin in a remarkably wide range of domestic and laboratory mammals and birds and is also a liver carcinogen in several species. However, it should also be noted that some species are quite resistant to the acute and carcinogenic effect of this material; of these, the mouse is so far resistant, and the sheep relatively resistant, to the acute effects.

\section{Clinical toxicity in cattle and calves}

Cases of poisoning of cattle and calves attributed to aflatoxin showed that, when a highly toxic meal was fed, calves to 6 months of age were highly susceptible and deaths occurred (Loosmore \& Markson, ig6r). Older cattle were more resistant, although deaths were reported with store cattle, and loss of appetite and rapid drop in milk yields in lactating cows (Loosmore, Allcroft, Tutton \& Carnaghan, I964; Hornby, Miller \& Dabell, r 962 $a, b$; Clegg \& Bryson, 1962).

Sheep are apparently resistant to the dose levels possible with the feeding of contaminated groundnut meal, and field outbreaks have been suspected but not confirmed (Lewis, Markson \& Allcroft, i967).

\section{Pathology}

Cattle and calves. The experimental feeding of toxic groundnut meal to calves, confirmed the post-mortem findings from clinical cases, and established that the 
lesions did show many features previously described as diagnostic for ragwort poisoning, including bile duct proliferation, megalocyte formation and venoocclusive lesions (Loosmore \& Markson, 1961). However, some differences in the histopathology of the lesion were detected (Allcroft \& Lewis, I963).

Sheep. No clinical cases have been recorded nor did experimental feeding of toxic groundnut meal produce any recognizable liver changes. However, of five sheep fed for periods of up to 5 years, one developed a liver tumour, and two others, tumours of the nasal cavity (Lewis et al. 1967).

\section{Results of experimental feeding trials}

Cattle. A study was made with calves and beef cattle, on the effects of different levels of toxic groundnut meal in the diet on the growth and weight gains (Horrocks, Burt, Thomas \& Lancaster, 1965). In this experiment, using early-weaned Ayrshire bull calves, a toxic meal containing $5 \cdot 0-6 \cdot 0 \mathrm{ppm}$ aflatoxin $\mathrm{B}_{1}$, was included in the concentrate ration at a level of $4 \%$ or $8 \%$. The effect was to significantly depress the live-weight gain, and food intake, in animals less than 3 months old. From this experiment, it was concluded that the lowered live-weight gain was due to lowered food intake and to impaired food utilization. Examination of the livers post mortem showed minimal liver cell damage, which was more marked in the group fed at the higher level. In beef cattle (Aberdeen Angus cross steers and heifers of 2-2.5 years of age) the inclusion of the same toxic groundnut meal at a level of from $4 \%$ to I $2 \%$ of the concentrate ration, when the concentrate intake was from 5.4 to $5.9 \mathrm{~kg}$ daily for 20 weeks, had no effect on the live-weight gain. Examination of the livers post mortem revealed only minimal changes in livers of animal in the group fed the highest level of the toxic meal. Horrocks et al. (1965) recommended the complete exclusion of groundnut meals containing appreciable amounts of aflatoxin from the diets of dairy cows and calves, and the limited use in diets of older store and fattening cattle.

In a recent study on the effect of feeding known quantities of aflatoxins to beef cattle (Garrett, Heitman \& Booth, 1968) fifty cross-bred steers, 6-8 months old, were fed rations containing cottonseed meal and aflatoxins for $\mathrm{r}_{33}$ days. The aflatoxins were produced by growing known toxin-producing strains on rice grains. The steers were divided into groups of ten, and diets comprised control, and four containing aflatoxins to give a level of $0.10,0.30,0.70$ and $1.00 \mathrm{ppm}$ in the feed.

In this trial two of the steers fed $\mathrm{r} \cdot 00 \mathrm{ppm}$ died, and weight gains were significantly lower in groups fed the highest levels of aflatoxin, but no apparent abnormalities were seen in the livers in the group receiving 0.10 and $0.30 \mathrm{ppm}$.

The effect of feeding rations, containing up to $20 \%$ of a strongly toxic groundnut meal to calves, first-calf heifers and older cows was described by Allcroft \& Lewis (1963). This experiment used an extremely toxic sample of groundnut meal, which had been the cause of deaths of pigs and calves (Carnaghan \& Allcroft, 1962). All the calves which received I $8 \%$ of toxic groundnut meal in their concentrate mixtures and which were fed at the rate of $0.9 \mathrm{~kg}$ a day gradually increasing to $\mathrm{I} \cdot 7 \mathrm{~kg}$ a day by 6 weeks died (or were killed) between the I6th and $25^{\text {th }}$ week of the experiment. Examination post mortem showed severe fibrosis of the liver, ascities and viscera] 
oedema. Histopathological examination of the liver showed centrolobular necrosis, bile-duct cell proliferation and venous occlusions.

Of the heifers, no loss of condition was noted after 7 months, and no clinical abnormality was seen in the older cows, but in a group of eight cows a significant fall in milk yield resulted from the feeding of a concentrate ration containing $15 \%$ of this very toxic groundnut meal.

A marked drop in milk yield in field cases has been reported (Loosmore et al. 1964).

\section{Results of experiments on the metabolism of aflatoxin in ruminants}

Allcroft \& Carnaghan (1963) showed that cows fed toxic groundnut meal, containing aflatoxin $B_{1}$, excreted in their milk a toxic factor, which caused liver changes in ducklings indistinguishable from those produced by aflatoxin. de Iongh, Vles \& van Pelt (1964) showed that the toxicity of this milk resided in a blue-violet fluorescent compound, termed the 'milk toxin'. 'These workers demonstrated the conversion of aflatoxin $B_{1}$ into 'milk toxin' in the lactating rat, and Butler \& Clifford (1965) showed the presence of this compound as well as aflatoxin $B_{1}$ in the livers of rats given pure aflatoxin $B_{1}$, which indicated that at least some aflatoxin $B_{1}$ was converted by the liver into the 'milk toxin'. Further work has established the structure of the milk toxin (Holzapfel, Steyn \& Purchase, i 966).

The metabolism and excretion of aflatoxin following a single dose of purified mixed aflatoxins has been studied in the lactating sheep and cow. Following the demonstration of aflatoxin $M_{1}$ in the milk of lactating cows fed diets of toxic groundnut meal (Allcroft \& Roberts, 1968), further studies were made on the metabolism of aflatoxin in the lactating ewe and cow.

Lactating cows. In the cow, urine, faeces and milk were collected over a period of 9 days, following the oral administration of a single dose of $300 \mathrm{mg}(0.5 \mathrm{mg} / \mathrm{kg})$ of mixed aflatoxins $\left(\mathrm{B}_{1} 44 \%, \mathrm{G}_{1} 44 \%, \mathrm{~B}_{2} 2 \%\right)$. The aflatoxin in the urine and faeces was estimated by the methods described for the sheep (Nabney, Burbage, Allcroft $\&$ Lewis, 1967 ), and the amounts of aflatoxin were assayed by thin-layer chromatography by the method of de Iongh $e$ t al. (1964).

Of the dose administered, only $4.52 \%$ was accountable to excretion, and of this the urine contained $\mathrm{I} \cdot 55 \%$, the faeces $2 \cdot 79 \%$ and the milk $0 \cdot 18 \%$. Only aflatoxin $M_{1}$ was found in the milk, and this represented $0.35 \%$ of the aflatoxin $B_{1}$ ingested. It has been shown that $M_{1}$ is derived from $B_{1}$.

Aflatoxin $M_{1}$ was also the main component excreted in the urine, while the faeces contained chiefly aflatoxin $B_{1}$. Aflatoxin $G_{1}$ was excreted both in urine and faeces, but none was detected in the milk. Excretion of aflatoxin from the cow is rapid, as $85 \%$ of the total in the milk and urine is excreted within $48 \mathrm{~h}$; none was detected after 4 days in the milk, or after 6 days in urine or faeces.

Lactating ewes. Following a single oral dose $(1 \mathrm{mg} / \mathrm{kg})$ of mixed aflatoxins $\left(\mathrm{B}_{1}\right.$ $36 \%, \mathrm{G}_{1} 52 \%, \mathrm{~B}_{2} 3 \%, \mathrm{G}_{2} 2 \%$ ) (Nabney et al. 1967 ) to ewes, only $8 \cdot 1 \%$ of the total dose was recovered, the milk containing $0.1 \%$, the urine $6.4 \%$ and the faeces $r \cdot 6 \%$. Some unchanged aflatoxins, $B_{1}$ and $G_{1}$, were found in the faeces, but only 
trace amounts in the milk and urine. Aflatoxin $M_{1}$ was excreted by all three routes, mainly in the urine, but was the major aflatoxin component in milk and faeces. Aflatoxin $G_{1}$ was excreted chiefly in the urine and faeces with only a trace in the milk.

Of the total excretion, about $90 \%$ of the aflatoxin excreted in the milk and urine occurred in the first $48 \mathrm{~h}$, and none could be detected in milk after 6 days or in the urine and faeces after 8 and 9 days respectively.

Comparison of cows and ewes. A comparison can be made between the results of excretion of aflatoxins in cows and ewes. These studies show that $M_{1}$ is excreted in the milk of both species in approximately the same proportion, and that this represents the conversion from $\mathrm{B}_{1}$ of $0.25 \%$ for the sheep and $0.35 \%$ in the cow. Following doses of $\mathrm{I} \mathrm{mg} / \mathrm{kg}$ in the sheep and $0.5 \mathrm{mg}$ in the cow, of mixed aflatoxins, very small amounts of $B_{1}$ or $G_{1}$ were found in the sheep's milk but none in the cow's milk. This finding may reflect the excretion of unmetabolized aflatoxins.

The urine showed the largest differences in excretion pattern between these species. The sheep excreted a much greater proportion of $M_{1}$ and $G_{1}$ in the urine than did the cow. However, the cow's urine contained significant amounts of $B_{1}$, but this is virtually absent in the sheep.

In the faeces, more $B_{1}$ was excreted unchanged in the cow than the sheep, with approximately similar amounts of $\mathrm{M}_{1}$ and $\mathrm{G}_{1}$ in both species.

The presence of greater amounts of unchanged $B_{1}$ in the urine and faeces of the cow than in that of the sheep suggests that $B_{1}$ is being metabolized to a greater extent by the sheep than by the cow, and that the relative resistance of sheep to the acute effects of aflatoxin is due to a greater detoxicating activity in the liver. Further evidence of a qualitative difference in metabolism between these species is provided by the demonstration of a further metabolite, 'aflatoxin $U$ ' from sheep urine, and it is suggested that this is a hydroxylation product of $G_{1}$ (Nabney et al. 1967).

These findings for excretion of aflatoxin $M_{1}$ in the lactating cow have been confirmed and extended by Masri, Garcia \& Page (1969), who fed known amounts of aflatoxins $B_{1}$ to six cows, and examined the excretion of the metabolite $M_{1}$ in the milk.

Daily increasing doses of aflatoxin $\mathrm{B}_{1}$, derived from a culture of $A$. flavus grown on rice, were fed for periods of $\mathrm{I} 4$ days to 6 weeks, in doses of from $5 \mathrm{mg}$ per day increasing to $80 \mathrm{mg}$ per day and the percentage of the aflatoxin $\mathrm{B}_{1}$ excreted as the metabolite $\mathrm{M}_{1}$ varied from 0.49 to $3 \cdot 94$.

The highest levels of $M_{1}$ in the milk were recorded in the $3^{\text {rd week of feeding }}$ from a cow that had received increasing daily doses of from $0.06 \mathrm{mg}$ to $29.4 \mathrm{mg}$ of aflatoxin $\mathrm{B}_{1}$. Its milk yield dropped rapidly, and lactation ceased in the 4 th week. Pooled milk for the week following withdrawal contained $0.020 \mathrm{ppm}$ aflatoxin $\mathbf{M}_{1}$, in contrast to $0.120 \mathrm{ppm}$ for the previous week. The milk yield of another of these cows decreased by the 6th week, but rose after withdrawal of the aflatoxin. Aflatoxin $B_{1}$ was invariably detected in the thin-layer chromatography of milk extracts, but mainly in too small amounts to quantitate reliably (0.002-0.020 ppm). Some aflatoxin $\mathrm{M}_{1}$ was found in the milk 7 days after withdrawal, but the amount had greatly 
decreased, in one instance from 0.055 to $0.001 \mathrm{ppm}$ and in another from 0.045 to $0.005 \mathrm{ppm}$.

Aflatoxin $\mathrm{M}_{1}$ was also found in the faeces and urine in amounts comparable to those excreted in the milk.

\section{Discussion}

The mycotoxins considered in this paper demonstrate the remarkable biological actions of certain metabolites of some strains of fungi, and at the same time the amount of detailed investigation needed to establish this information.

In comparing the toxicity for ruminants, ergot is the least toxic, and Ioo $\mathrm{g}$ of ergot sclerotia were fed daily for I I days to produce the characteristic lesions in adult cattle (Cunningham, 1949). In contrast both sporidesmin and aflatoxin are active in amounts of a few milligrammes (Mortimer \& Stanbridge, 1968; Allcroft, 1965; Masri et al. 1969).

Both sporidesmin and aflatoxin are potent hepatotoxins and have been shown to be excreted through the bile, sporidesmin producing necrosis of the bile-duct epithelium. With aflatoxin there is marked bile-duct proliferation and later bileduct cysts. Cyst-adenomas are produced in the rat and ferret (Lancaster et al. 1961; Barnes \& Butler, 1964; Allcroft \& Lancaster, 1969).

The effect of aflatoxin in inhibiting protein synthesis in the liver cell has been described (Rees, I966), but the exact mechanism of the liver cell necrosis is not known. It seems therefore that the necrotizing and carcinogenic effects may not be directly related to each other.

The careful studies on the metabolism of aflatoxin in the ruminant by Allcroft and her colleagues (Allcroft \& Carnaghan, 1963; Allcroft \& Roberts, 1968; Nabney et al. 1967) have shown the excretion in the milk of the metabolite, aflatoxin $\mathrm{M}_{1}$. However, the low conversion, approximately $4 \%$, and the fact that even after giving sufficient aflatoxin to produce clinical effects, only traces of unchanged aflatoxin $B_{1}$ are found (Masri et al. 1969) suggests that in practice the hazard to man from this source is small. However, as long as there is the possibility of pockets of aflatoxins in feedstuffs, then there is a remote chance that the feeding for a short time of a highly toxic meal, could result in the excretion in the milk and a drop in milk yield, a combination which has been shown to give rise to the highest level of secretion in the milk (Masri et al. 1969). Such milk could find its way into human food. So far, there is no published evidence to associate liver tumours in man directly with aflatoxin, though further detailed studies may reveal a link. However, as has been suggested, man may well be as resistant as the mouse (Lancaster, 1968).

\section{Control of mycotoxins in feedstuffs}

These three mycotoxins can only be controlled in the primary product. In the case of ergot, because of the size of the fungal sclerotia, recognition is not difficult. Sporidesmin however, presents the very difficult problem of the control of a pasture saprophyte, while in the case of aflatoxin, control is being directed at reducing contamination to a minimum at harvest, followed by rapid drying and good storage. 
The hazard to man

No residues have been detected in carcasses of cattle fed ergot (Cunningham, McIntosh \& Swan, 1944) nor of sporidesmin in sheep (Mortimer \& Stanbridge, I968). With aflatoxin, carcass residues can be detected and the metabolite, aflatoxin $M_{1}$ is excreted in the milk of cows and sheep given large doses of aflatoxin $B_{1}$. Such a potent carcinogen should be excluded from human food.

In looking at the general problem of mouldy feeds for ruminants it is of interest to recall that although some fungi produce highly toxic metabolites, others are now being examined as possible economic sources of protein, for both animals and man; while the fungal digestion of cellulose and lignin could be an advantage in the preparation of animal feedstuffs.

In farm practice, the greatest difficulty lies in controlling the fungal species present on the feedstuff and controlling their growth both before and after storage. Very much more work is needed before the toxicity, both acute and chronic, can be determined for all the common groups of fungi and their strains. At present it is known both that mycotoxins may be present in a sterile feedstuff and that the cultivation of a toxigenic strain does not necessarily mean that the feedstuff is toxic. In clinical outbreaks, often all the contaminated foodstuff has been consumed before the clinical features are seen. In all suspected cases of mycotoxicosis it is important to be able to reproduce the condition by feeding the suspected foodstuff, and then to be able to produce the clinical and pathological features by feeding the suspected fungus and its metabolic products. Without this study it is not possible to incriminate mycotoxins as a cause, in ruminants, of such multi-factorial conditions as infertility, drop in milk yield or poor growth.

I hope this review will stimulate interest and investigation into this subject.

I am grateful to Dr R. Allcroft for much information and detailed discussion at all the stages in the preparation of this paper.

\section{REFERENCES}

Agricultural Research Council et al. (1962). Toxicity Associated with Certain Batches of Groundnuts : Report of the Interdepartmental Working Party on Groundnut Toxicity Research.

Allcroft, R. (1965). In Mycotoxins in Foodstuffs, p. 153. [G. N. Wogan, editor.] Cambridge, Mass: Massachussets Institute of Technology Press.

Allcroft, R., Carnaghan, R. B. A., Sargeant, K. \& O'Kelly, J. (196I). Vet. Rec. 73, 428.

Allcroft, R. \& Carnaghan, R. B. A. (1963). Vet. Rec. 75, 259.

Allcroft, R. \& Lancaster, M. C. (1963). Excerpta med. int. Congr. Ser. no. 80.

Allcroft, R. \& Lancaster, M. C. (1969). Vet. Rec. (In the Press.)

Allcroft, R. \& Lewis, G. (1963). Vet. Rec. 75, 487 .

Allcroft, R. \& Roberts, B. A. (1968). Vet. Rec. 82, I 16.

Asplin, F. D. \& Carnaghan, R. B. A. (1961). Vet. Rec. 73, 1215.

Assao, 'T., Buchi, G., Abdel-Kader, M. M., Chang, S. B., Wick, E. L. \& Wogan, G. N. (1963). $\mathcal{F}$. Am. chem. Soc. 85, 1706.

Barger G. (1931). Ergot and Ergotism. Edinburgh: Oliver and Boyd.

Barnes J. M. \& Butler, W. H. (1964). Nature, Lond. 202, 1016.

Blount, W. P. (I96r). Turkeys 9, 52.

Butler, W. H. \& Barnes, J. M. (1963). Br. F. Cancer 17, 699.

Butler, W. H. \& Clifford, J. I. (1965). Nature, Lond. 206, 1045. 
Carnaghan, R. B. A. (1965). Nature, Lond. 208, 308.

Carnaghan, R. B. A. \& Allcroft, R. (I962). Vet. Rec. 74, 925.

Clegg, F. G. \& Bryson, H. (1962). Vet. Rec. 74, 992.

Cunningham, I. J. (1949). Aust. vet. F. 25, 27.

Cunningham, I. J., McIntosh, I. G. \& Swan, J. B. (1944). N.Z. Fl Sci. Technol. Sect. A $26,125$.

Cunningham, I. J., Swan, J. \& Hopkirk, C. S. M. (1944). N.Z. Yl Sci. Technol. Sect. A 26, I21.

de Iongh, H., Vles, R. O. \& van Pelt, J. G. (1964). Nature, Lond. 202, 466.

Dring, J. C. (I955). Unpublished report (copies from Commonwealth Bureau of Animal Health, Weybridge, Surrey).

Garrett, W. N., Heitman, H. \& Booth, A. N. (1968). Proc. Soc. exp. Biol. Med. 127, 188.

Halver, J. E. (1965). In Mycotoxins in Foodstuffs, p. 209. [G. N. Wogan, editor.] Cambridge, Mass: Massachussets Institute of Technology Press.

Hartley, R. D., Nesbitt, B. F. \& O'Kelly, J. (1963). Nature, Lond. 198, 1056.

Holzapfel, C. W., Steyn, P. S. \& Purchase, I. F. (1966). Tetrahedron Lett. no. 25, p. 2799.

Hopkirk, C. S. M. (1936). N.Z. Fl Agric. 53, ro5.

Hornby, R. B., Miller, J. C. \& Dabell, J. S. (1962a). Vet. Rec. 74, 52.

Hornby, R. B., Miller, J. C. \& Dabell, J. S. (1962b). Vet. Rec, 74, 189.

Horrocks, D., Burt, A. W. A., Thomas, D. C. \& Lancaster, M. C. (I965). Anim. Prod. 7, 253.

Lancaster, M. C. (1968). Cancer Res. 28, 2288.

Lancaster, M. C., Jenkins, F. P. \& Philp, J. McL. (I96I). Nature, Lond. r92, 1095.

le Breton, E., Frayssinet, C. \& Boy, J. (1962). C.r. Acad. Sci., Paris 255, 784.

Lewis, G., Markson, L. M. \& Allcroft, R. (1967). Vet. Rec. 80, 3 I 2.

Loosmore, R. M., Allcroft, R., Tutton, E. A. \& Carnaghan, R. B. A. (1964). Vet. Rec. 76, 64.

Loosmore, R. M. \& Harding, J. D. J. (I961). Vet. Rec. 73, 1362.

Loosmore, R. M. \& Markson, L. M. (1961). Vet. Rec. 73, 81 3 .

Masri, M. S., Garcia, V. C. \& Page, J. R. (1969). Vet. Rec. 84, 146.

Mortimer, P. H. \& Stanbridge, T. A. (r968). f. comp. Path. 78, 505.

Nabney, J., Burbage, M. B., Allcroft, R. \& Lewis, G. (1967). Fd Cosm. Toxicol. 5, I1.

Newberne, P. (1965). In Mycotoxins in Foodstuffs, p. 187. [G. N. Wogan, editor.] Cambridge, Mass: Massachussets Institute of Technology Press.

New Zealand Society of Animal Production (1959). Proc. N.Z. Soc. Anim. Prod. r9, 44.

Rees, K. R. (1966). Proc. R. Soc. Med. 59, 755 .

Roe, F. J. C. \& Lancaster, M. C. (1964). Br. med. Bull. 20, 127.

Sargeant, K., Sheridan, A., O'Kelly, J. \& Carnaghan, R. B. A. (i961). Nature, Lond. 192, 1096.

van der Zijden, A. S. M., Koelensmid, W. A. A. B., Boldingh, J., Barrett, C. B., Ord, W. O. \& Philp, J. (1962). Nature, Lond. 195, 1060.

Wogan, G. N. (1966). Bact. Rev. 30, 460. 